\title{
HEAT TRANSFER ENHANCEMENT USING POROUS MATERIAL
}

\author{
S.B.Gawas ${ }^{1}$ and S. V. Vanjari ${ }^{2}$
}

\begin{abstract}
The present experimental work is done to investigate forced convection heat transfer rate through porous material. Stainless steel ball of diameter 8,12 and $16 \mathrm{~mm}$ are used to study the effects of porosity and mass flow rate on heat transfer rate. Atmospheric air is used as cooling medium. Three test beds are made of stainless steel ball with different diameter. Dimensions of test bed is $100 \mathrm{~mm} \times 50 \mathrm{~mm} \times 50 \mathrm{~mm}(\mathrm{~L} \times \mathrm{B} \times \mathrm{H})$. The experimental work shows that heat transfer rate increases with mass flow rate and decreases with porosity.
\end{abstract}

Keywords - Heat transfer, porous material, porosity, rate of heat transfer

\section{INTRODUCTION}

Heat transfer through porous material has a great scope in chemical, mechanical, aerospace, medical, biological engineering, materials sciences \& many more fields. Due to increase in contact surface with fluid and efficient heat transfer property, Porous material being a part of interest of many researches. Number of Experiments, analytical work, researches has been done to investigate heat transfer phenomena through porous materials such as sintered metals, foams (metal or polymeric), ceramics, etc.

Recent advances in electronic system, heat exchangers, chemical reactors, etc; have lead to dramatic increases in heat flux. Heat transfer through porous media is being explored to thermal management of such systems. Many studies \& experimental work have reported that Heat transfer through porous media is more efficient techniques than traditional one.

\section{LITERATURE REVIEW}

Heat transfer through porous medium was extensively investigated in the past decades by lots of researches and scholars.

Jian Yang et. al.(2010) [1] packed bed reactors are widely used in chemical process industries, because of their low cost and ease of use compared to other packing methods. However, the pressured rops in such packed beds are usually much higher than those in other packed beds, and the overall heat transfer performances may be greatly lowered. In order to reduce the pressure drops and improve the overall heat transfer performances of packed beds, structured packed beds are considered to be promising choices. In this paper, the flow and heat transfer inside small pores of some novel structured packed beds are numerically studied, where the packed beds with ellipsoidal or nonuniform spherical particles are investigated for the first time and some new transport phenomena are obtained. Three-dimensional Navier-Stokes equations and RNG k-e turbulence model with scalable wall function are adopted for present computations. The effects of packing form and particle shape are studied in detail and the flow and heat transfer performances in uniform and non-uniform packed beds are also compared with each other. Firstly, it is found that, with proper selection of packing form and particle shape, the pressure drops in structured packed beds can be greatly reduced and the overall heat transfer performances will be improved. The traditional correlations off low and heat transfer extracted from randomly packings are found too verpredict the pressured ropes and Nusselt number for all these structured packings, and new correlations of flow and heat transfer are obtained. Secondly, it is

${ }^{1}$ Department of Mechanical Engineering SSPM's College of Engineering, Kankavli, Maharashtra, India

${ }^{2}$ Department of Mechanical Engineering SSPM's College of Engineering, Kankavli, Maharashtra,India 
also revealed that, both the effects of packing form and particle shape are significant on the flow and heat transfer in structured packed beds. With the same particle shape (sphere), the overall heat transfer efficiency of simple cubic (SC) packing is the highest. With the same packing form, such as face center cubic (FCC) packing, the overall heat transfer performance of long ellipsoidal particle model is the best. Furthermore, with the same particle shape and packing form, such as body center cubic (BCC) packing with spheres, the overall heat transfer performance of uniform packing model is higher than that of non-uniform packing model. The models and results presented in this paper would be useful for the optimum design of packed bed reactors.

Tsotsas (2010a) [2] has well summarized the axial heat dispersion characteristics in the packed tubes. It is demonstrated that, axial dispersion of heat in packed tubes with fluid flow is not due to the effective thermal conductivity alone, but to a combination of heat transport in the direction of flow, heat transfer between particle surface and fluid, and heat conduction inside particles. For low Peclet number, axial dispersion of heat is mainly due to the effective thermal conductivity; for middle Peclet number, the effect of fluid-to-particle heat transfer should be dominate; and for high Peclet number, the heat conduction in the particles prevails.

Tsotsas (2010b) [3] has also well summarized the effective thermal conductivity models for the packed beds. It shows that, the effective thermal conductivity of packed beds is related to a variety of factors, including thermal conductivities of particles and fluid, porosity of packed bed, particle shape, particle size distribution, mechanical properties of particles, thermodynamic properties of fluid, etc.

A.P. Collier et. al. [4] studied that the heat transfer coefficient has been measured for a heated phosphor-bronze sphere (diam. 2.0, 3.0 or $5.56 \mathrm{~mm}$ ) added to a bed of larger particles, through which air at room temperature was passed. The bronze heat transfer sphere was attached to a very thin, flexible thermocouple and was heated in a flame to $140{ }^{\circ} \mathrm{C}$ before being immersed in the bed. The conclusion of this study is that for the commoner situation of $\mathrm{ds} / \mathrm{db}$, h rises to a maximum, when $\mathrm{U}$ slightly exceeds $\mathrm{Umf}$. This is because a hot (relatively large) particle then loses heat by being in contact with very many of the smaller fluidized particles. When $(\mathrm{ds} / \mathrm{db})$ changes from being less than unity to well above unity, there is thus a change of mechanism from heat transfer to the gas flowing through the bed to heat transfer to the other particles. Some factors affecting this change of mechanism must include:

1. When $(\mathrm{ds} / \mathrm{db})$ is decreased below unity, the number of contacts between the heat transfer sphere and the other fluidized particles becomes smaller.

2. When (ds>db), it is possible that a smaller heat transfer sphere is fluidized, when the other particles in the bed are not. Consequently, a progressively smaller (and consequently more mobile) heat transfer sphere contacts the fluidized particles for shorter times, making heat transfer to the other particles less likely.

3. The magnitude of the Reynolds number for the gas flowing over the bronze heat transfer sphere is important, in that heat transfer to the gas is favored by a large Re, as in this work.

\section{EXPERIMENTAL SETUP}

The experimental set up for investigation of heat transfer rate in the porous material is shown in Fig. 1. It consists of an air flow circuit, a test section, electric heater, flow meter, and temperature sensor. In the present study, air will be induced to the wind tunnel by a centrifugal suction blower and the inlet temperature is read by a thermometer. Before entering the test section, the air flow will be heated by passing through a removable electric heater and then transverses the test section, where the particles inside will be heated by the hot air. When the test section temperature will be stabilized, the atmospheric air will be passed into the channel and test section is cooled down until its temperature decreases to the ambient temperature. During the cooling process, the experimental data will be measured and recorded simultaneously. The volumetric flow rate through the test section will be measured by a flow meter, which will be situated at the downstream of the test section. The static pressure difference across the test section will be displayed by a micro-differential meter combined with inclined manometer. The air flow and particle temperatures will be measured by PT100 thermocouples. 


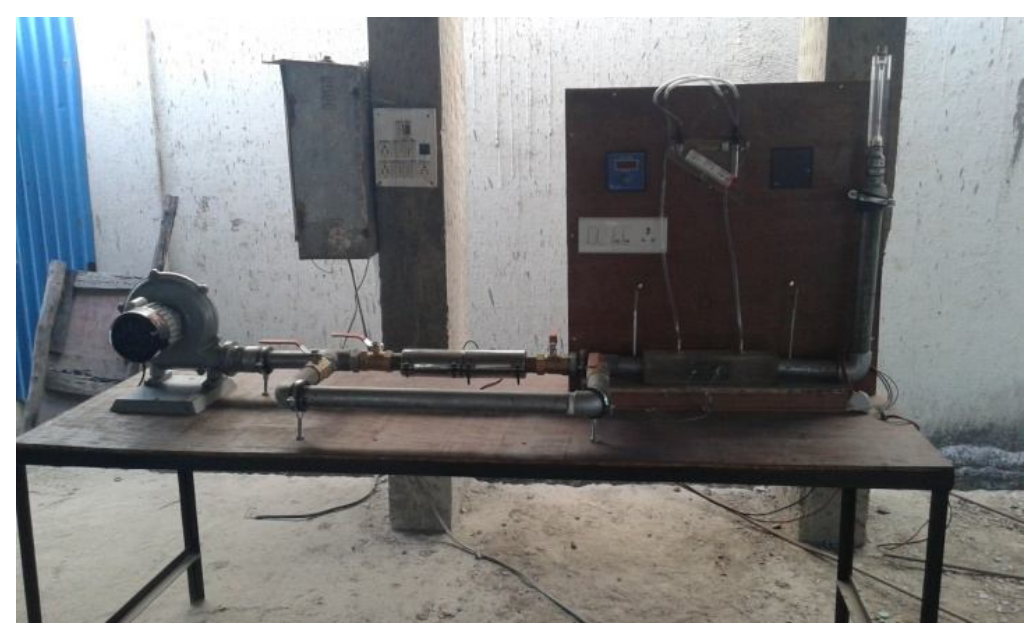

Figure 1: Experimental setup

A.

\section{Test section -}

As shown in Fig.2, the test section is made of Acrylic Sheet plates (thickness of 10mm) and stainless steel balls are orderly stacked inside. In present study, the test section is composed of $100 \mathrm{~mm}$ X $50 \mathrm{~mm} \mathrm{X} 50 \mathrm{~mm}$ packed cells, which would guarantee the fully developed flow and heat transfer inside. Three different diameters are used to maintain different porosity. $8 \mathrm{~mm}, 12 \mathrm{~mm}$ and $16 \mathrm{~mm}$ balls are used with SC structure.

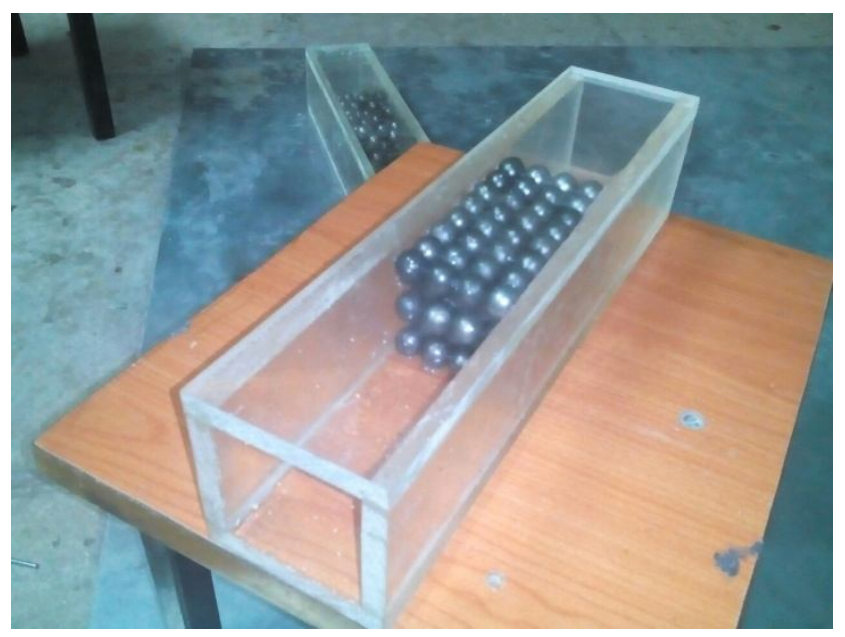

Figure 2: Test Section

\section{CALCULATIONS \& FORMULAE}

For the sake of validating the present experimental data, it has been compared with that reported in literature Ergun (1952), Wakao and Kaguei, (1982) for the steady flow, which is given by

$$
f=\frac{c_{1}}{R e}+c_{2}
$$

$$
N u_{\mathrm{sf}}=a_{1}+a_{2} \operatorname{Pr}^{1 / 3} \operatorname{Re}^{n}\left(\frac{d_{\mathrm{P}}}{d_{\mathrm{h}}} \phi\right)^{n}
$$

Where C1, C2 are the friction factor constants, with C1and C2 in Ergun's equation (Ergun, 1952); a1, a2 and n are the heat transfer model constants, with a1, a2 and n in Wakao's equation (Wakao and Kaguei, 1982). 
IV. OBSERVATION TABLE

Table 1 Reading for $8 \mathrm{~mm}$ dia, $200 \mathrm{lph}$

\begin{tabular}{|c|c|c|c|c|c|c|c|}
\hline \multicolumn{8}{|c|}{ For Bed to Air } \\
\hline$d=8 \mathrm{~mm}$ & & & Flow ra & $=200 \mathrm{Ip}$ & & & $\mathrm{OW}$ \\
\hline \multirow{3}{*}{ Sr. No. } & \multirow{3}{*}{$\begin{array}{r}\text { Time } \\
\text { Interval } \\
\text { (mins) }\end{array}$} & \multicolumn{6}{|c|}{ Temperature $\left({ }^{\circ} \mathrm{C}\right)$} \\
\hline & & Air inlet & \multicolumn{4}{|c|}{ Bed } & Air \\
\hline & & t1 & t2 & t3 & t4 & t5 & t6 \\
\hline 1 & 0 & 35.5 & 78.5 & 78 & 78 & 78 & 44 \\
\hline 2 & 10 & 35.5 & 65 & 65.5 & 65.5 & 66 & 42.8 \\
\hline 3 & 20 & 35.5 & 56 & 56.2 & 56.2 & 56 & 41.5 \\
\hline 4 & 30 & 35.8 & 49 & 49 & 49 & 48.5 & 40 \\
\hline 5 & 40 & 35.8 & 47 & 47 & 47 & 47 & 38.5 \\
\hline 6 & 50 & 36 & 45.5 & 45.5 & 45.5 & 45 & 37.2 \\
\hline
\end{tabular}

Table 2 Reading for $12 \mathrm{~mm}$ dia, $200 \mathrm{lph}$

\begin{tabular}{|c|c|c|c|c|c|c|c|}
\hline \multicolumn{8}{|c|}{ For Bed to Air } \\
\hline \multicolumn{2}{|c|}{$\mathrm{d}=12 \mathrm{~mm}$} & \multicolumn{3}{|c|}{ Flow rate $=200 \mathrm{Iph}$} & \multicolumn{3}{|c|}{$q=400 W$} \\
\hline \multirow{3}{*}{ Sr. No. } & \multirow{3}{*}{$\begin{array}{r}\text { Time } \\
\text { Interval } \\
\text { (mins) }\end{array}$} & \multicolumn{6}{|c|}{ Temperature $\left({ }^{\circ} \mathrm{C}\right)$} \\
\hline & & Air inlet & \multicolumn{4}{|c|}{ Bed } & Air \\
\hline & & $\mathrm{t} 1$ & t2 & t3 & t4 & t5 & t6 \\
\hline 1 & 0 & 35 & 79 & 78 & 78 & 78 & 42.5 \\
\hline 2 & 10 & 35 & 68.5 & 68.5 & 68.5 & 69 & 40.8 \\
\hline 3 & 20 & 35.5 & 62 & 62 & 62 & 62 & 39.5 \\
\hline 4 & 30 & 35.5 & 58 & 58 & 58 & 58.5 & 38 \\
\hline 5 & 40 & 35.5 & 55.5 & 55.5 & 55 & 55 & 37.2 \\
\hline 6 & 50 & 36 & 54 & 54 & 54 & 54 & 36.8 \\
\hline
\end{tabular}

Table 3 Reading for $16 \mathrm{~mm}$ dia, $200 \mathrm{lph}$

\begin{tabular}{|c|c|c|c|c|c|c|c|}
\hline \multicolumn{8}{|c|}{ For Bed to Air } \\
\hline \multicolumn{2}{|c|}{$\mathrm{d}=16 \mathrm{~mm}$} & \multicolumn{4}{|c|}{ Flow rate $=200 \mathrm{lph}$} & \multicolumn{2}{|c|}{$q=400 W$} \\
\hline \multirow{3}{*}{ Sr. No. } & \multirow{3}{*}{$\begin{array}{r}\text { Time } \\
\text { Interva } \\
\text { (mins) }\end{array}$} & \multicolumn{6}{|c|}{ Temperature $\left({ }^{\circ} \mathrm{C}\right)$} \\
\hline & & Air inlet & \multicolumn{4}{|c|}{ Bed } & Air \\
\hline & & $\overline{\mathrm{Ti}}$ & t2 & t3 & t4 & t5 & To \\
\hline 1 & $\overline{0}$ & 35.5 & 78 & 78 & 78.5 & 79 & 42 \\
\hline 2 & 10 & 35.5 & 71 & 70.5 & 70.5 & 70.5 & 41 \\
\hline 3 & 20 & 35.5 & 64 & 64 & 64 & 64 & 39.5 \\
\hline 4 & 30 & 36 & 59 & 59 & 59 & 59 & 38 \\
\hline 5 & 40 & 36 & 54.5 & 54.5 & 54.5 & 55 & 37.5 \\
\hline 6 & 50 & 36 & 51 & 51 & 51 & 52 & 36.8 \\
\hline
\end{tabular}




\section{RESULT \& DISCUSSION}

The heat transfer rate is calculated for different porosities and different mass flow rate.

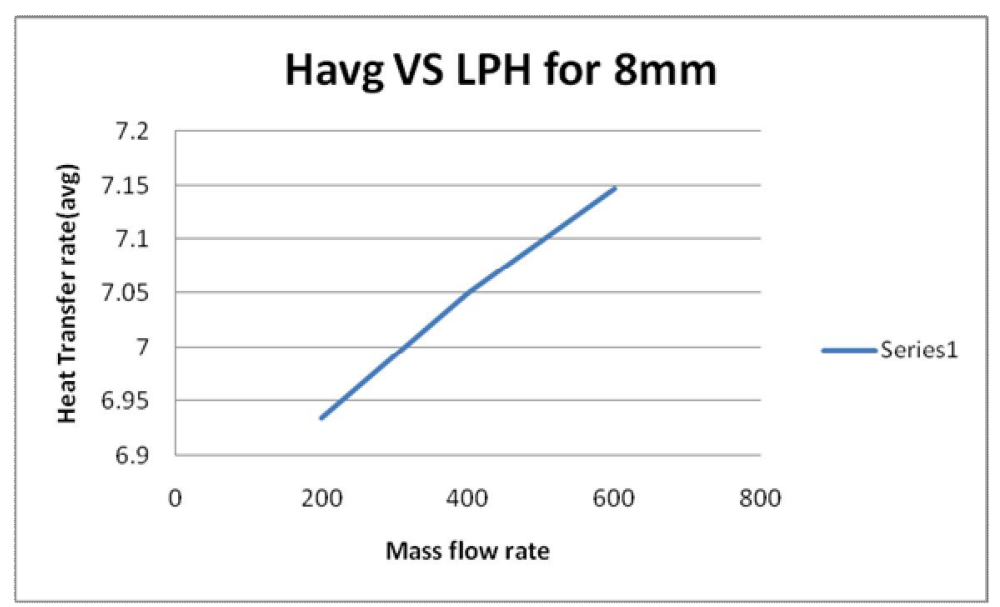

H (avg) VS Mas flow rate for $8 \mathrm{~mm}$

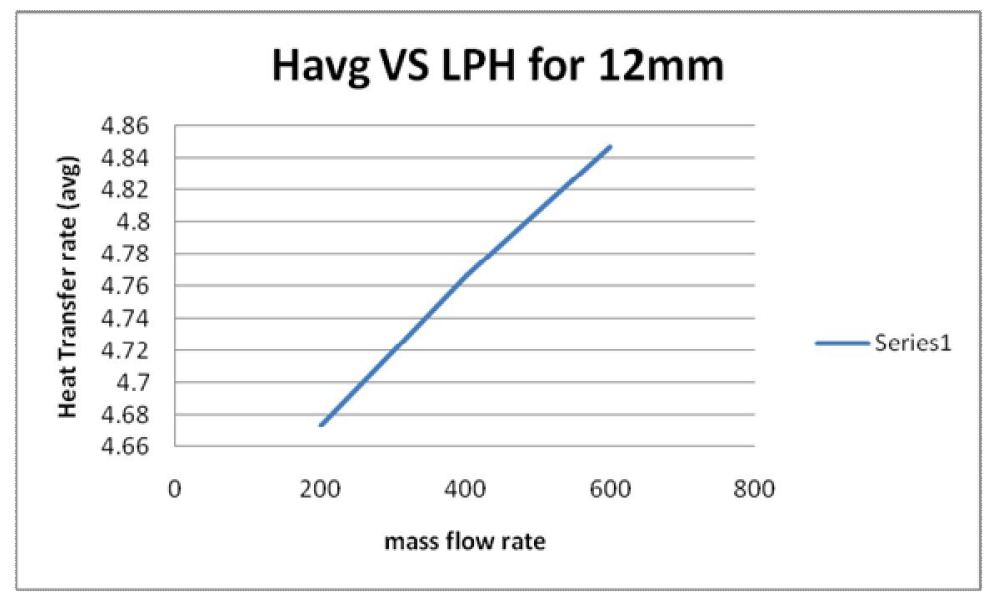

H (avg) VS Mas flow rate for $12 \mathrm{~mm}$

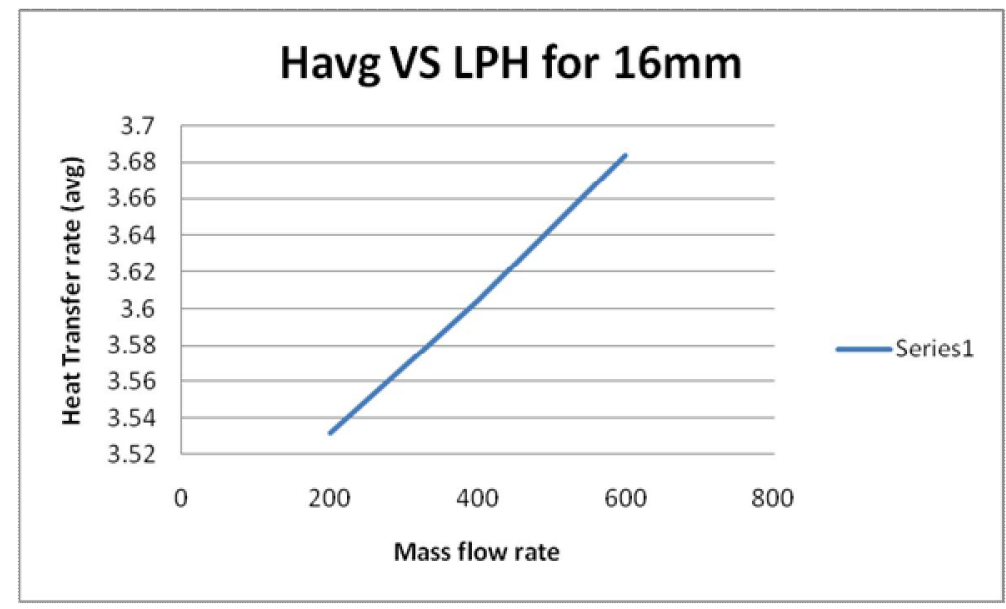

$\mathrm{H}(\operatorname{avg})$ VS Mas flow rate for $12 \mathrm{~mm}$ 
Another graphs are also plots for porosity verses heat transfer rate for different mass flow rate.
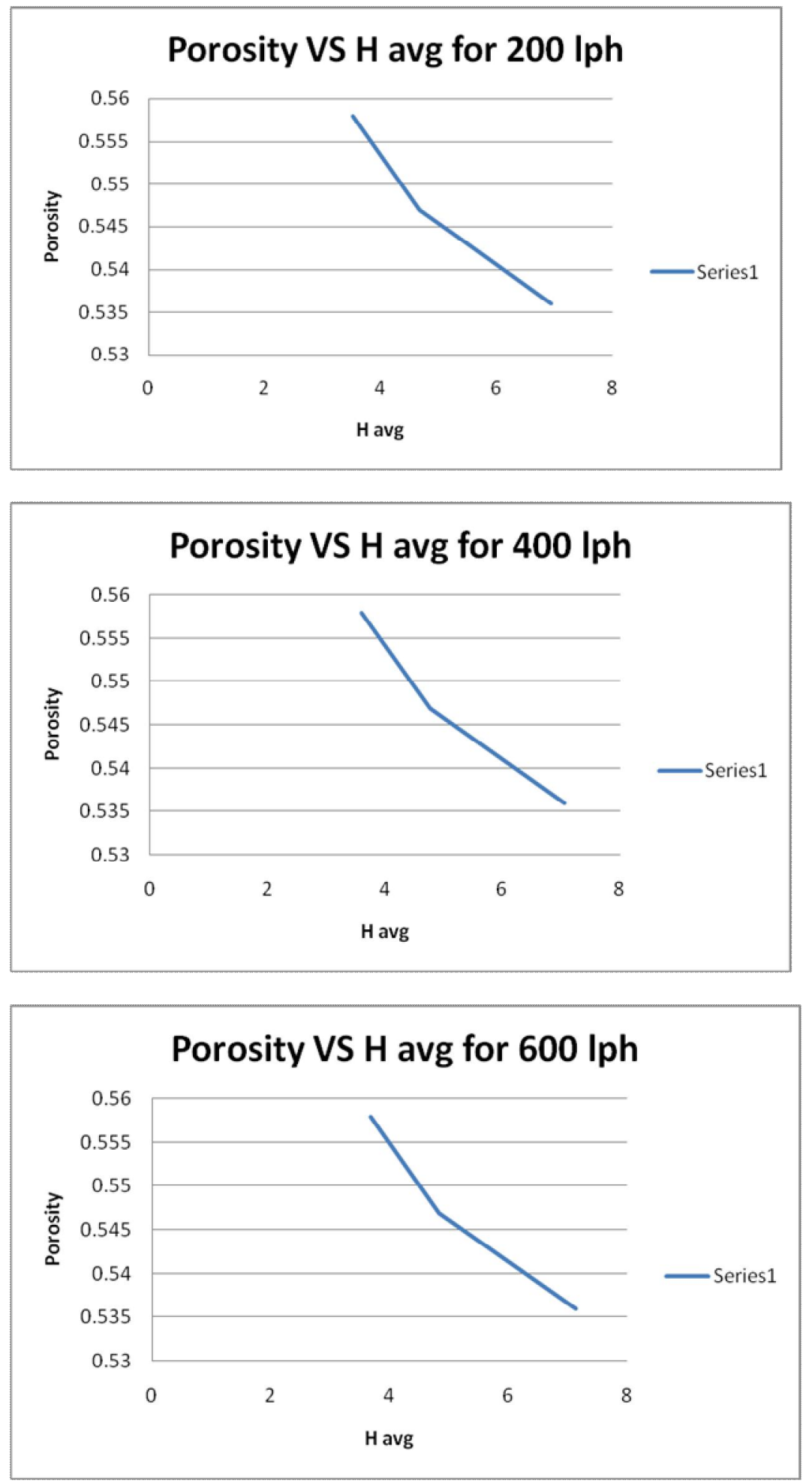


\section{CONCLUSION}

After investigating the present study and plotting graphs we can conclude that;

1. Heat transfer rate is increase with decrease in porosity.

2. As flow rate is increase heat transfer rate is also increase.

\section{REFERENCES}

[1] Yang J., Wang Q. W., Zeng M., Nakayama A., 2010. Computational study of forced convective heat transfer in structured packed beds with spherical or ellipsoidal particles. Chem. Eng. Sci. 65 (2), 726-738.

[2] Tsotsas E., 2010a. Heat and mass transfer in packed beds with fluid flow. In:Stephan, P.(Ed.), VDI Heat Atlas., Springer, Heidelberg, pp.1327-1341.

[3] Tsotsas, E., 2010b. Thermal conductivity of packed beds. In: Stephan, P. (Ed.), VDI Heat Atlas., Springer, Heidelberg, pp. 570-580.

[4] A.P. Collier, A.N. Hayhurst, J.L. Richardson, S.A. Scott, 'The heat transfer coefficient between a particle and a bed (packed or fluidised) of much larger particles', Chemical Engineering Science 59 (2004) 4613 - 4620.

[5] Dong sheng Wen, Yulong Ding, "Heat transfer of gas flowthrough a packed bed", Chemical Engineering Science 61 (2006) 3532 - 3542.

[6] M.E. Trivizadakis, D. Giakoumakis, A.J. Karabelas, "A study of particle shape and size effects on hydrodynamic parameters of trickle beds”, Chemical Engineering Science 61 (2006) $5234-5243$.

[7] Lanfrey, P.Y., Kuzeljevic, Z.V., Dudukovic, M.P., 2010. Tortuosity model for fixed beds randomly packed with identical particles. Chem. Eng. Sci. 65(5), 1891-1896.

[8] Nijemeisland M., Dixon A.G., 2004. CFD study of fluid flow and wall heat transfer in a fixed bed of spheres. AIChEJ. 50 (5), 906-921. 